\title{
Turkish nursing students' perceptions and experiences of bullying behavior in nursing education
}

\author{
Serap Palaz \\ Department of Labor economics and Industrial relations, Balikesir University, Turkey
}

Correspondence: Serap Palaz. Address: Bandırma İ.̇̇.B.F Çalışma Ekonomisi Bölümü. Telephone: 02-667-380-945. Email: serappalaz@balikesir.edu.tr

Received: March 15, 2011

DOI : 10.5430/jnep.v3n1p23

\author{
Accepted: April 12, 2012 \\ Published: January 1, 2013 \\ URL: http://dx.doi.org/10.5430/jnep.v3n1p23
}

\begin{abstract}
Objective: This descriptive study aimed to determine the bullying and harassment experiences of nursing students' in various Nursing Schools in Turkey. The types and frequency of bullying behaviors, the sources of bullying behaviors, and students' emotions towards these experiences were investigated.

Methods: Study participants were 370 undergraduate nursing students from four different Turkish Nursing Schools. To estimate bullying at nursing school I used a short version of the Negative Acts Questionnaire that adapted according to the earlier studies on bullying against nursing students particularly those conducted by Cooper et al. and Celik and Bayraktar.

Results: A total of 222 respondents (60\%) reported that they had experienced at least one of the thirteen bullying behaviors at daily and weekly frequencies during the last six months. Work related bullying was the most frequently encountered type of bullying behaviors which is followed by personal related bullying behaviors. Also, an interesting result from this study is that most students reported clinic nurses as their bully, indicating that the perpetrators were mostly females and older than them.

Conclusions: This study supports previous reports of bullying against Turkish student nurses and adds to the scant body of literature showing that nursing students often experience bullying and harassment from clinical nurses (horizontal bullying), and importantly, this may influence their future employment choices.
\end{abstract}

\section{Key words}

Workplace bullying, Harassment, Student nurses, Nursing education

\section{I ntroduction}

The concept of workplace bullying sometimes referred as mobbing ${ }^{[1]}$, workplace abuse ${ }^{[2]}$, victimization ${ }^{[3]}$, workplace harassment ${ }^{[4]}$, and verbal abuse ${ }^{[5]}$ refers to situations where a person repeatedly and eventually feels subjected to negative treatment on the part of one or more persons, and where the person(s) exposed to the treatment have difficulty in defending themselves against these actions ${ }^{[6]}$. Also all various constructs applied in the literature to describe the phenomenon of systematic and prolonged mistreatment at work share that the experienced aggression has harmful effects on targets' health and well-beings. 
Bullying and harassment in the workplace are not new phenomena however there are growing epidemic of bullying in the health sector which is raising great interest among employers, health care workers, and governmental agencies across the world ${ }^{[7]}$. For the reason that explained by Zapf et al. ${ }^{[8]}$ health sector jobs such as nursing profession require a high level of personal involvement which means that sensing and expressing emotions and building up personal relationships. The higher the level of personal involvement and the more personal information is available, the more possibilities for being attacked exist. Also in health sector, it is difficult to evaluate or appraise jobs objectively and this lack of objectivity offers a lot of opportunity for attacking each other. Although nurses often come across bullying and harassment in the healthcare environment, they are reluctant to complain because they tend to accept it as just "part of the job". Therefore workplace abuse in the healthcare sector is severely underreported ${ }^{[9,10]}$.

National and international literature reveal that the prevalence of bullying and harassment in the health sector workplace is a well-known problem and the risk of being subjected to psychological violence among nurses is three times higher than the ones in other professional groups in the service sector ${ }^{[11,12]}$. Also it is quoted that nursing students have the highest risk of experiencing aggression because of inexperience, frequent ward changes and the challenge of meeting new environments ${ }^{[5]}$. Although The World Health Organizations, the International Council of Nurses, and Public Services International recognize the incidence of violent episodes as a major health priority, the number of nurses affected by this problem still continues to rise ${ }^{[7,13]}$.

Bullying and harassment are emotional issues for nurses who are exposed to abusive behaviors and have negative influences on both their own physical and psychological health and the quality of service they provide. Especially, it was shown in the studies ${ }^{[14,15]}$ that when nursing students in practice setting encounter bullying behaviors, their approach to practice, as well as their intent to become a nurse can be affected. The nursing shortage is considered to be a world-wide problem and it is suggested that unhealthy work environments cause the recruitment and retention problems ${ }^{[16]}$. Yet there are limited researches on the phenomenon of bullying and harassment in the nursing education and the possible impact of this on future employment choices. The study of types, sources and frequency of bullying/mobbing behaviors encountered by Turkish nurses in the workplace attracted noticeable attention recently ${ }^{[17-21]}$. According to the best of our knowledge there has been paid a little attention to the investigation of bullying and harassment against nursing students in Turkey ${ }^{[14,22]}$. This present study attempts to make a contribution to redressing this gap by determining perceived bullying and harassment behaviors which are experienced by nursing students in four Turkish Nursing Schools.

\section{Materials and methods}

\subsection{Participants and settings}

The data of the study were obtained from four Nursing schools of four year undergraduate program which are affiliated to three different Turkish state universities. The sampling included only nursing students who were taking courses in 2nd, 3rd, and 4th grades. First year students were not included in the scope of the study because they have not started to gain clinical experience yet. The survey was anonymous and asked respondents to take part in the study between March and May in 2011. In total, 400 questionnaires were delivered and 374 of them returned. The initial examination of the returned questionnaires showed that four were incomplete; these were therefore excluded from the data analysis process. The number of usable questionnaires was 370 (92\%).

\subsection{Ethical Considerations}

The study was approved by the university ethics committee of researcher. Also before the research was initiated, legal permission was obtained from the administrations of each Nursing Schools. The questionnaires were administrated to the dropout students by one of the instructor at the nursing department. The purpose of the research was explained to them and they were instructed about their right to refuse if they wished to do so. In addition, respondents were informed that any 
information that they shared would be used only for scientific purposes. No information about the identity of the volunteers was required.

\subsection{Instruments}

To estimate bullying at nursing school I used a short version of the Negative Acts Questionnaire that adapted according to the earlier studies on bullying against nursing students particularly those conducted by Cooper et al. ${ }^{[23]}$ and Celik and Bayraktar ${ }^{[14]}$. The scale consists of thirteen items referring to personal related bullying (e.g., being shouted, spreading gossip, socially isolated), work related bullying (e.g., unmanageable workloads, hostility after or failure to acknowledge significant clinical or academic accomplishment), and physical intimidating forms of bullying (e.g., threats of violence or physical abuse, intimidating behavior such as finger pointing). The scale which had already been translated and validated in previous studies ${ }^{[14,24]}$ and the Cronbach alpha coefficient of the scale in this study was $>0.80$. Therefore, it is accepted that a short version of the Negative Acts Questionnaire as reliable and used it in statistical analyses.

The questionnaire was discussed and reviewed with three colleagues of Nursing Schools and their opinions were sought with regard to face validity. In addition, the questionnaire was piloted with 30 nursing students to determine its understandability and the students were able to complete all items in an average of 20 minutes and did not recommend any changes. Therefore no revisions to the questionnaire were indicated, and data from the pilot study were not included in this study.

All items are given in behavioral terms with no reference to the phrase "bullying", thus measuring perceived exposure to bullying behaviors without forcing the respondents to label these situations as bullying. For each item, the respondents are asked how often they have been exposed to the specific behavior during the last 6 months. The response categories are "never”, “now and then”, "about monthly”, “about weekly”, and "about daily”.

\subsection{Data analysis}

Data analysis was performed using the Statistical Package Program for the Social Sciences (SPSS version 11.5). The frequency and percentage distributions analysis were used to accomplish objectives which stated in the first section of the study.

\section{Findings}

The findings on demographic characteristics of the study group are as follows; of 370 nursing students in the sample, the majority were females (77.8\%), and nearly all of them were single (97.02\%), more than half of the respondents were aged 21 to 23 years (66.7 \%). The majority of respondents did not have any nursing experiences at all (95.4\%). More than half of the nursing students' place of birth and place where they lived so far were rural areas (village and little town). Most students' accommodation were dormitory and sharing houses with friends $(\mathrm{N}=284,76.6 \%)$.

A total of 222 respondents (60\%) reported that they had experienced at least one of the thirteen bullying behaviors at daily and weekly frequencies during the last six months. As mentioned before NAQ scale consists of 5-likert type rating but in this analysis, the five response categories were subsequently combined into three categories: never, now and then/monthly, and weekly/daily. According to the definition of bullying and harassment which was clarified in Section 2, responses listed as weekly/daily may best express bullying and harassment, while now and then/monthly may express isolated incidences of negative behaviors. Table 1 shows the frequency and the percentage of bullying behaviors as occurring weekly/daily and never basis. The most common bullying behaviors were "negative and disparaging remarks about nursing’s profession” (11.85 \%), “unmanageable workloads or unrealistic deadlines” (8.37\%), and "given a bad grade as a punishment" (5.67\%). "Assignments, task or rotation responsibilities made for punishment rather than educational purposes”, "being shouted at or being the target of anger”, "inappropriate, nasty, rude or hostile behavior", 
"belittling, and spreading of gossip and rumors" were the following most frequent reported forms of negative behaviors in present study.

Table 1. Bullying Behaviors’ Reported by the Study Group $(n=370)$ Frequency categories n (\%)

\begin{tabular}{lll}
\hline Reported Bullying Behaviors' & Never & Weekly/Daily \\
\hline Being shouted at or being the target of spontaneous anger (or rage) & $27(7.29 \%)$ & $11(2.97 \%)$ \\
Inappropriate, nasty, rude or hostile behaviour & $136(36.75 \%)$ & $18(4.86 \%)$ \\
Belittling or humiliating behaviour & $116(31.35 \%)$ & $17(4.59 \%)$ \\
Spreading of gossip and rumours about you & $217(58.64 \%)$ & $16(4.32 \%)$ \\
Cursing and swearing & $287(77.56 \%)$ & $10(2.70 \%)$ \\
Negative and disparaging remarks about nursing's profession & $103(27.83 \%)$ & $42(11.85 \%)$ \\
Assignments, task, work or rotation responsibilities made for punishment rather & $179(48.37 \%)$ & $21(5.67 \%)$ \\
than educational purposes & $164(44.32 \%)$ & $21(5.67 \%)$ \\
Given a bad grade as a punishment & $12(3.24 \%)$ \\
Hostility after or failure to acknowledge significant clinical, research or academic \\
$\begin{array}{l}\text { accomplishment } \\
\text { Threats of violence or physical abuse or actual abuse }\end{array}$ & $222(60 \%)$ & $4(1.08 \%)$ \\
Being ignored and excluded or socially isolated & $308(83.24 \%)$ & $14(3.78 \%)$ \\
Unmanageable workloads or unrealistic deadlines & $189(51.08 \%)$ & $31(8.37 \%)$ \\
Intimidating behaviour such as finger-pointing, invasion of personal space, & $158(42.70 \%)$ & $5(1.35 \%)$ \\
shoving, blocking/barring the way & $323(87.29 \%)$ & \\
\hline
\end{tabular}

A majority of the students reported that clinic nurses were the most frequently source of bullying behaviors (70.8\%). Some of the students denoted that they had been exposed to bullying behaviors from the Lecturers (29.5\%), the School (29.2\%), doctors (21.1\%), patients (20.8\%), and classmates (19.7\%). On the other hand, hospital staffs, patients' relative, and visitors seem to be the minor source of bullying and harassment according to the students' perception. Moreover, most of the students reported that the perpetrators were older than them (86.17\%) and they were predominantly female (92.4 \%).

Table 2. Effects of Bullying on Victim

\begin{tabular}{lll}
\hline & \% & N \\
\hline Feeling of extreme fatigue or exhaustion & 66.4 & 246 \\
Getting angry & 91.5 & 339 \\
Thinking about leaving profession & 52.97 & 196 \\
Diminishing school performance & 58.37 & 216 \\
Becoming forgetful & 46.21 & 271 \\
Losing self confidence & 56.48 & 209 \\
Loss of concentration & 71.34 & 264 \\
Insomnia & 47.56 & 176 \\
Reducing motivation & 70.8 & 262 \\
Increasing consumption of alcohol and & 26.48 & 98 \\
cigarette & & \\
Impossible to bear criticism & 49.45 & 183 \\
Panic attack & 34.58 & 128 \\
Dysfunction social life & 40.53 & 150 \\
Damaging physical health & 38.37 & 142 \\
Feeling guilty & 39.45 & 146 \\
\hline
\end{tabular}

As seen from the Table 2, bullying and harassment had a strong effect on students both physical and psychological health. The most common results of abuse were that students felt anger (91.4\%), lost their concentration (71.34\%), decreased their motivation (70.8\%), and felt exhaustion (66.4\%). Also nursing students reported that their school performance was 
negatively affected as a result of bullying and harassment (58.37\%). Perhaps the most disturbing result is that $52.97 \%$ of nursing students choose/prefer "thinking about leaving profession".

\section{Discussion}

This study was carried out in four Nursing Schools which located in the western part of the country and discussed the nature, severity, frequency and sources of bullying experienced by students gaining both academic education and clinical experience. More than half of the respondents were exposed to bullying during their education (60\%). These results are consistent with the previous studies involving nursing students which found that bullying and harassment at nursing education is an important problem and that such bullying behaviors have detrimental effects ${ }^{[10,25]}$.

The result of present study supports the findings of previous Turkish study of Celebioglu et al. ${ }^{[12]}$ which found that $50.3 \%$ of the students were subjected to violence in the clinical settings. Verbal violence (91.6\%) was the most frequently encountered type of abuse, followed by physical violence (4.2\%), and sexual abuse (4.2\%). In addition, another study which was undertaken by Celik and Bayraktar ${ }^{[14]}$ investigating the abuse experiences of nursing students found that verbal abuse was the most frequently reported type of abuse with all participants reported being behaved in an inappropriate, nasty, rude, or hostile way, being yelled at, and being humiliated or belittled.

It is found in this study that work related bullying (e.g., negative and disparaging remarks about nursing's profession, unmanageable workloads, assignments, task or rotation responsibilities made for punishment rather than educational purposes) was the most frequently encountered type of bullying behaviors, 34.80\% in total, followed by personal related bullying (e.g., being shouted, spreading gossip, socially isolated), $23.22 \%$ in total. On the other hand, only very small amount of respondents (only $2.43 \%$ ) reported physical intimidating forms of bullying (e.g., threats of violence or physical abuse, intimidating behavior such as finger pointing). Nursing students reported that work related bullying was the most annoying problem for them but this finding needs to be read carefully because it is possible that students in general do not understand assignments, workload and deadlines as a consequence of the learning environment. Responses were only based on student perceptions and therefore it is unknown whether the behaviors are actually occurring or whether grades and workloads which are fairly given are perceived by students as being punishing. In any case, student perceptions of being exposed to bullying and harassment are of concern given the potential negative impact on student health and academic performance ${ }^{[23]}$.

An interesting result from this study is that most students reported clinic nurses as their bully, indicating that the perpetrators were mostly females and older than them. In previous Turkish studies, the abusive behaviors considered were mainly those committed by patients and their relatives, and classmates ${ }^{[12,14]}$. In present study, nursing students rarely reported bullying and harassment on the part of patients and their relatives and classmates. The reasons might account for using different sample from different part of the country, with different characteristics of participants. For instance, the study of Celebioglu et al ${ }^{[12]}$ was carried out in a nursing school where located in the eastern part of the country, and the sample in the study of Celik and Bayraktar ${ }^{[14]}$ included nursing students from Ankara where is in the middle of the country. Turkey is a large country and there are huge cultural differences between western and eastern side of the country, therefore, a nationwide survey of the students of different nursing schools will be needed for investigating the nature and sources of bullying phenomenon to be further developed.

On the other hand, in consistent with the present study that nurse-on-nurse bullying is a significant workplace problem that depends on the flow of power within the workplace. Bullying within nursing is primarily intra-professional (i.e. between nurse and nurse) and horizontal violence is common in nursing and the victims are especially the younger students and student nurses ${ }^{[26-28]}$. It is proposed that external pressures are often held responsible, such as health care workers' requirement to find a scapegoat for errors as a reason for the existence of bullying behavior towards nursing students ${ }^{[26]}$. Recent change in health sector in Turkey which involves adaptation requirements for the issue of accreditation and patient 
rights and the financing of hospitals on output-based formula which leads to greater levels of alertness in the hospital patient population increased workloads for nurses. Therefore, increased stress and pressure on clinical nurses might cause increased tendency of bullying student nurses in the clinical settings.

Longo ${ }^{[15]}$ states that when nursing students in a practice setting encounter horizontal bullying and harassment, their approach to practice, as well as their intent to become a nurse, can be influenced. Likewise, the findings of the present study show that nursing students who experienced bullying behaviors felt anger and lost their concentration, their social life was affected badly, and they even thought of leaving profession as a consequence. The nursing shortage is considered to be a world-wide problem and in many countries, including Turkey, facing a shortage of nurses. According to the OECD report, Turkey takes the last place among 51 countries in European region in terms of the number of nurses per 1000 individuals. In other words, Turkey had the fewest nurses having fewer than five nurses per 1000 in the Europe ${ }^{[29]}$. This alarming fact suggests that further research is needed to clarify the extent of nursing students' experiences of bullying and the practical effects of them on their choices.

\section{Study limitations}

Some methodological limitations of the present study need to be mentioned. Firstly, the data reported are based on self-reports which suggest problems with both common method variance and issues of validity in the classification of victims as presented by Einarsen et al ${ }^{[30]}$. This type of research enables measuring only perceptions, not the actual behaviors and this study is subject to single-ratter bias as only the students' responses have been considered. The present study does not include any information from the nursing school's staff and the hospital's staff or independent observers confirming the victimization reported. Therefore, it would be more beneficial if multiple data collection methods and multiple ratters are used in the future study.

Secondly, the number of people participated into the study located in one certain part of the country and although they were representative of the total population of nursing students in this area the obtained results could not be generalized. Future research could focus on larger samples from different nursing schools in all over the country. In addition, students in the western part of the country where the present research took place may not be more likely to experience aggressive incidents than those in some parts of the Turkey which are more rural and have less educated population. In the future, across cultural study can be more instrumental in investigating bullying and harassment at nursing school.

Finally, as mentioned in the study of Ferns and Meerabeau ${ }^{[5]}$ questionnaire approaches may be accused of bias due to an unrepresentative sample because people who do not return questionnaires frequently differ from those who do. But, in this study the response rate is quite high (92\%) this may offer confidence in the findings.

\section{Conclusion}

The findings of the study have revealed that nursing students experience high levels of bullying and harassment during their education. Work related bullying was the most frequently encountered type of bullying behaviors followed by personal related bullying behaviors. It is seen that bullying in nursing education is detrimental to the health and well-being of students, and to the provision of quality nursing care. This study supports previous reports of bullying against Turkish student nurses ${ }^{[12,14]}$ and adds to the scant body of literature showing that nursing students often experience bullying and harassment from clinical nurses (horizontal bullying), and importantly, this may influence their future employment choices. Moreover, although educators need to be sensitive to its occurrence and assist students to deal with it, our findings show that the school and lecturer are also the considerable source of the bullying behaviors. Nursing students were exposed to bullying and harassment in both the practice settings and the educational settings, as suggested by Randle ${ }^{\text {[31] }}$. There is concern that students may begin to assimilate this conduct into their practice, perpetuating the behavior. For this reason, the aspect of bullying in nursing education need to be crucially taken into consideration in order to stop bullying in 
nursing profession. The literature suggests that the first step in solving the workplace bullying problem is an educational intervention. Nursing staff and management need to be educated about bullying what bullying behaviors look like and how to deal with bullying. By raising awareness about the issue, healthcare staff may become less tolerant of this negative behavior ${ }^{[27,32]}$.

As recommended by the American Association of Colleges of Nursing Position Statement, all faculties (schools of nursing) prepare nurses to recognize and prevent all form of violence in the workplace. Nursing students also should be treated fairly and consistently, and with respect and dignity, wherever they study or undertake practice placements ${ }^{[33]}$. Therefore strategies to increase students' awareness of this problem and its potential consequences are indicated. Reliable procedures, education, follow up and organizational policies and clear statement of a "No Tolerance" approach are needed to diminish workplace bullying and to prevent its negative consequences.

\section{References}

[1] Leymann, H. Mobbing and psychological terror at workplaces. Violence and Victims. 1990; 5: 119-126. PMid:2278952

[2] Keashly, L. Emotional abuse in the workplace: Conceptual and empirical issues. Journal of Emotional Abuse. 1998; 1: 85-117. http://dx.doi.org/10.1300/J135v01n01_05

[3] Aquino, K., and Thau, S. Workplace victimization: Aggression from the target`s perspective. Annual Review of Psychology. 2009; 60: 717-741. PMid:19035831 http://dx.doi.org/10.1146/annurev.psych.60.110707.163703

[4] Brodsky, C. The harassed worker. Toronto: Lexington Books. DC Heath Company. 1976.

[5] Ferns, T., and Meerabeau, L. Verbal abuse experienced by nursing students. Journal of Advanced Nursing. 2007; 61(4): 436-444. PMid:18034811

[6] Einarsen, S. Harassment and bullying at work: A review of the Scandinavian approach. Aggression and Violent Behavior. 2000; 5: 379-401. http://dx.doi.org/10.1016/S1359-1789(98)00043-3

[7] Hinchberger, P.A. Violence against female student nurses in the workplace. Nursing Forum. 2009; 44(1): 37-46. PMid:19187052 http://dx.doi.org/10.1111/j.1744-6198.2009.00125.x

[8] Zapf D., Escartin J., Einarsen S., Hoel H., and Vartia M. Empirical findings on prevalence and risk groups of bullying in the workplace. In S. Einarsen, H. Z. Hoel, and C.L. Cooper (Eds.), Bullying and Harassment in the Workplace: developments in theory, research, and practice. Second Edition, New York: Taylor and Francis. 2011.

[9] Ferns, T. Under-reporting of violent incidents against nursing staff. Nursing Standard. 2006; 20(40): 41-45.

[10] Magnavita, N., Heponiemi, T. Workplace violence against nursing students and nurses: an Italian experience. Journal of Nursing Scholarship. 2011; 43(2): 203-210. PMid:21605325 http://dx.doi.org/10.1111/j.1547-5069.2011.01392.x

[11] Keely, B.R. Recognition and prevention of hospital violence. Dimensions of Critical Care Nursing. $2002 ; 21$ (6): $236-24$. PMid:12473904 http://dx.doi.org/10.1097/00003465-200211000-00004

[12] Celebioglu A., Akpinar R.B., Kucukoglu, and Engin R. Violence experienced by Turkish nursing students in clinical settings: their emotions and behaviors. Nurse Education Today. 2010; 30: 687-691. PMid:20129722 http://dx.doi.org/10.1016/j.nedt.2010.01.006

[13] Kuehn, B.M. Violence in health care settings on rise. Journal of the American Medical Association. $2010 ; 304(5): 511-512$. PMid:20682926 http://dx.doi.org/10.1001/jama.2010.1010

[14] Celik, S.S., and Bayraktar, N. A study of nursing student abuse in Turkey. Journal of Nursing Education. 2004; $43(7)$ : $330-336$. PMid:15303588

[15] Longo, J. Horizontal violence among nursing students. Archives of Psychiatric Nursing. 2007; 21(3): 177-178. PMid:17556112 http://dx.doi.org/10.1016/j.apnu.2007.02.005

[16] Gok, A. U., and Kocaman G. Reason for leaving nursing: A study among Turkish Nurses. Contemporary Nurse. 2011; 39(1): 75-84. PMid:21955267 http://dx.doi.org/10.5172/conu.2011.39.1.65

[17] Uzun, O. Perceptions and experiences of nurses in Turkey about verbal abuse in clinical settings. Journal of Nursing Scholarship. 2003; 35(1): 81-85. PMid:12701531 http://dx.doi.org/10.1111/j.1547-5069.2003.00081.x

[18] Oztunc, G. Examination of incidents of workplace verbal abuse against nurses. Journal of Nursing Care Quality. 2006; 21(4): 360-365. http://dx.doi.org/10.1097/00001786-200610000-00014

[19] Kisa, S. Turkish nurses` experiences of verbal abuse at work. Archives of Psychiatric Nursing. 2008; 22(4): $200-207$. PMid:18640539 http://dx.doi.org/10.1016/j.apnu.2007.06.013 
[20] Efe, S.Y. and Ayaz, S. Mobbing against nurses in the workplace in Turkey. International Nursing Review. 2010; 57: 328-334. PMid:20796062 http://dx.doi.org/10.1111/j.1466-7657.2010.00815.x

[21] Pinar, R., and Ucmak F. Verbal and physical violence in emergency departments: a survey of nurses in Istanbul, Turkey. Journal of Clinical Nursing. 2010; 20: 510-517. PMid:20969652 http://dx.doi.org/10.1111/j.1365-2702.2010.03520.x

[22] Celik, S.S., Celik, Y. Agirbas, and Ugurluoglu O. Verbal and physical abuse against nurses in Turkey. International Nursing Review. 20007; 54: 359-366.

[23] Cooper, J.R.M., Walker, J.T., Askew, R., Robinson J.C., McNair M. Students` perceptions of bullying behaviors by nursing faculty. Issues in Educational Research. 2011; 21(1): 1-21.

[24] Bilgel, N., Aytac, S., Bayram, N. Bullying in Turkish white-collar workers. Occupational Medicine. 2006; 56: $226-31$. PMid:16507600 http://dx.doi.org/10.1093/occmed/kqj041

[25] Magnussen, L., Amundson, M. J. Undergraduate nursing student experience. Nursing and Health Sciences. 2003 ; 5: $261-267$. PMid:14622377 http://dx.doi.org/10.1046/j.1442-2018.2003.00158.x

[26] Stevens, S. Nursing Workplace Retention: Challenging A bully Culture. Health Affairs. 2002; 21(5): 189-193. PMid:12224882 http://dx.doi.org/10.1377/hlthaff.21.5.189

[27] Lewis, M. Nurse bullying: organizational considerations in the maintenance and perpetration of health care bullying culture. Journal of Nursing Management. 2006; 14: 52-58. PMid:16359446 http://dx.doi.org/10.1111/j.1365-2934.2005.00535.x

[28] Curtis, J. Bowen I., and Reid A. You have no credibility: Nursing students`experiences of horizontal violence. Nurse Education in Practice. 2007; 7: 156-163. PMid:17689439 http://dx.doi.org/10.1016/j.nepr.2006.06.002

[29] OECD. Health at a Glance: Europe 2010, OECD Publishing. 2010. http://dx.doi.org/10.1787/health_glance-2010-en. last accessed, 15 March 2012.

[30] Einarsen, S., Matthiesen, S.B., and Skogstad A. Bullying, burnout and well-being among assistant nurses. Journal of Health Safety. 1998; 14(6): 563-568.

[31] Randle, J. Bullying in the nursing profession. Journal of Advanced Nursing. 2003; 43(4): 395-401. PMid:12887358 http://dx.doi.org/10.1046/j.1365-2648.2003.02728.x

[32] Johnson, S. International Perspectives on workplace bullying among nurses: A review. International Nursing Review. 2009; 56: 34-40. PMid:19239514 http://dx.doi.org/10.1111/j.1466-7657.2008.00679.x

[33] American Association of College of Nursing (AACN). Hallmarks of the Professional Nursing Practice Environment [Internet]. 2011. Available from: http://www.aacn.nche.edu/publications/positions/hallmarks.htm. last accessed, 15 March 2012. 